p556 Bigger and
better? EU expansion
is a mixed blessing for
clinical research.

\title{
Shift in NIH focus fuels basic researchers' fears
}

After years of flush funding, the budget for the US National Institutes of Health (NIH) is in a lean phase: the 2004 budget is $\$ 28$ billion, about $3 \%$ more than the previous year, and the 2005 budget, now winding its way through Congress, is not expected to be much bigger. Combined with the lower numbers, a strong emphasis on translational and interdisciplinary research is feeding scientists' fears about the future of investigator-driven basic science.

Under the NIH's much-publicized Roadmap for Medical Research, a total of $\$ 2.1$ billion will be diverted from individual institutes' budgets to new interdisciplinary projects and clinical research over the next five years (Nat. Med. 9, 1335; 2003). Meanwhile, applied research on infectious diseases, primarily for biodefense, would balloon to $\$ 1.7$ billion under the 2005 proposal and is likely to remain a high priority.

The boost in applied research comes at a particularly bad time. NIH accountants project an overall decline of nearly $6 \%$ in the agency's budget by 2009 because of the mushrooming federal deficit. For the 2005 NIH budget, Congress is already poised to trim up to $\$ 2.3$ billion from the administration's modest request.

Congress also earmarks portions of the budget for research on specific conditions. “There's a lot of pressure [for NIH earmarks] from a lot of different advocacy groups, from juvenile diabetes to Parkinson's," says Democratic congressman Sherrod Brown. For instance, Brown, who sits on the House appropriations committee, plans to insert a demand for new tuberculosis therapies.

As politicians increasingly clamor for concrete results, however, researchers say they are worried about the future of traditional investigator-initiated basic research.

"It does look like a withdrawal of research funds from basic research to put into things that are almost product-oriented," says Ira Mellman, professor of cell biology at Yale University. "It seems they want to get the individual investigators to act like a biotech company, coming up with stuff that can be sold or turned into a diagnostic test, [but] my experience is that academic researchers are not very effective when it comes to that kind of thing," he says.
Others say the NIH is not qualified to oversee such projects. "The NIH has never been good at deciding what to work on," says Vincent Racaniello, a virologist at Columbia University in New York. "The best work comes from letting scientists follow their own paths."

Racaniello is particularly critical of biodefense. "Pouring money into biodefense research is just a load of crap," he says. "[It] is just another
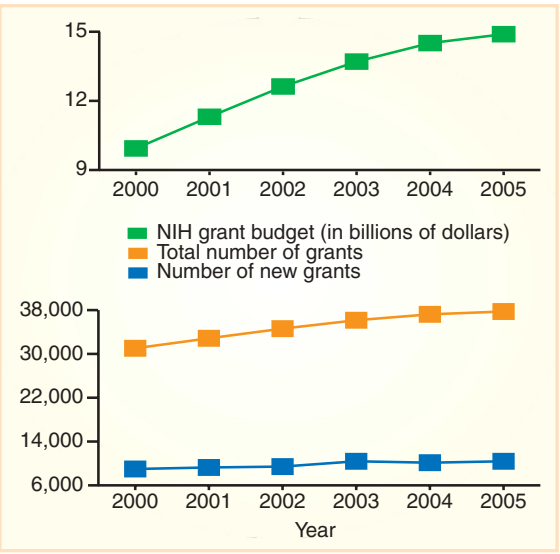

Level lines: The number and amount of $\mathrm{NIH}$ grants has seen only marginal increases.

political ploy and a waste of NIH dollars."

Norka Ruiz Bravo, the NIH's deputy director for extramural research, says the researchers' fears are overblown. "There's certainly an interest in translational research," she says, "[but] overall NIH's commitment to investigator-initiated research isn't diminished at all."

According to an analysis by the American Association for the Advancement of Science, however, the number of multiyear research project grants would increase $1.4 \%$ in the proposed 2005 budget, but only when measured against the low 2004 numbers. The average grant size is expected to increase by $1.3 \%$, against a $3.5 \%$ expected inflation rate in the cost of biomedical research. Taken together, the numbers suggest that traditional NIH grants are getting smaller and more difficult to obtain.

Even the new disease-specific programs are poorly conceived and "no thought is being given to oversight," says Saul Silverstein, a microbiologist at Columbia University. "The money will be eaten up by those who can assemble what looks like a cohesive program, but will never be judged as such."

Alan Dove, New York

\section{Europe's clinical trial database criticized}

The much-disputed European directive on clinical trials went into effect on 1 May (Nat. Med. 9, 1336; 2003), but some experts are warning against the restricted access provided to its new clinical trial database.

The database will include general information on a clinical trial, recommendations of the trial's ethics committee and any amendments to the protocol. At the end of the trial, researchers must also enter whether a trial ended early because of safety issues or lack of efficacy. To maintain confidentiality, the directive stipulates that the database will be accessible only to the relevant authorities of the states, the London-based European Agency for the Evaluation of Medicinal Products and the European Commission.

Because the database is not available to other researchers or to the public, however, experts warn that it will allow scientists to selectively publish favorable results.

"This is a missed chance to disclose the information which can prevent us from using biased information," says Frank Buntinx, president of the Centre for Evidence-Based Medicine in Leuven, Belgium.

The directive has strong support from pharmaceutical companies. "Only authorities should have access to the database since the information could be of high economic value for other pharmaceutical companies," says Uwe Dolderer, a spokesman for the German Pharmaceutical Industry Association.

Buntinx notes that similar information, from both publicly and privately funded trials, is freely available in the US as a result of increasing concerns over the nondisclosure of negative studies and early termination of trials. Xavier Bosch, Barcelona 